\title{
Coblation Assisted Endoscopic Excision of Juvenile Nasopharyngeal Angiofibroma- An Institutional Observational Study
}

\author{
Rout K. ${ }^{1}$, Mani K.J. ${ }^{2}$, Sahoo P.R. ${ }^{3}$ \\ ${ }^{1}$ Dr. Khageswar Rout, Associate Professor, ${ }^{2}$ Dr. Kumari Jyoti Mani, Postgraduate Student, ${ }^{3}$ Dr. Pradipt Ranjan Sahoo, Assistant \\ Professor; All authors are affiliated with Department of ENT, Kalinga Institute of Medical Sciences, Bhubaneswar, Odisha, \\ India.
}

Corresponding Author: Dr. Pradipt Ranjan Sahoo, Department of ENT, Kalinga Institute of Medical Sciences, Bhubaneswar, Odisha, India. E-mail-dr.pradipt1407@gmail.com

\begin{abstract}
Objective: The purpose of our case series is to highlight the role of coblation in endoscopic JNA excision in terms of blood loss, duration of surgery and hospital stay. This was a Retrospective study done at Kalinga Institute of Medical Sciences, Bhubaneswar, Odisha between January 2014 to June 2019 which includes 12 patients of JNA. Material and Method: The present case series was of 12 cases of JNA removal by endoscopic approach using coblation. Proper history taking and clinical examination was done in all cases. All patients were male between age group 5 to 20 years in the present series. In all patients preoperative CECT and MRI was done and staged according to Radkowski staging system. Out of 12 patients, 9 patients (Radkowski stage IB, IIA \& IIB) were operated without embolization \& 3 patients (Radkowski stage IIB \& IIIA) were embolized $24 \mathrm{hr}$ before operation. Result: The present study suggests that coblation decreases the chances of intraoperative bleeding, provides clear surgical field thus reduces operative time. Coblation helps in debulking of tumor, preserving anatomical integrity, increases chance of complete removal and reduces the recurrence. Coblation decreases use of frequent and multiple instrumentation. So use of coblation in JNA removal (with or without preoperative embolization) gives advantage of safe and effective results. Conclusion: Hence, none of the 12 patients required post-operative blood transfusion and follow-up showed no complications in any of the cases.
\end{abstract}

Keywords: Coblation, Embolization, Endoscopic, Juvenile Nasopharyngeal Angiofibroma.

\section{Introduction}

Juvenile Nasopharyngeal Angiofibroma is a benign, locally aggressive, highly vascular tumor accounts for $0.05 \%-0.5 \%$ of all head and neck neoplasms primarily affecting adolescent males, the average age of presentation being around 14 to 18 years [1-4]. It was first described in 1847 by Chelius who stated that fibrous nasal polyp commonly occurs in persons around the time of puberty [5]. First morphologic and clinical description of this neoplasm was given in 1878 by Bensch [5]. The term juvenile nasopharyngeal angiofibroma was given by Chaveau in 1906 due to its early submucosal extension towards the nasopharynx, as it occurs mostly in juvenile age group and histologically consist of vascular and fibrous components [1,5].Various etiologic mechanism including vascular, hormonal and genetic factors are responsible for development of JNA. The high level of androgen receptor expression, vascular endothelial growth factor and transforming growth factor indicates initiation and growth of the lesion [6].

Manuscript received: $\mathbf{2 6}^{\text {th }}$ November 2019

Reviewed: $6^{\text {th }}$ December 2019

Author Corrected: $14^{\text {th }}$ December 2019

Accepted for Publication: $17^{\text {th }}$ December 2019
The diagnosis of JNA is based on history and nasal endoscopic examination. The clinical presentation depends on the anatomical location of the tumor and extension at the time of diagnosis. Unilateral progressive nasal obstruction (usually painless) and intermittent unprovoked epistaxis are the most common symptom of small to intermediate size JNA [1,7]. In advanced lesion swelling of cheek, proptosis or headache may be present, which indicates involvement of the infratemporal fossa, the orbit or the cranial fossa respectively [7]. The nasal endoscopic examination of JNA shows a smooth, firm, lobulated, hypervascular mass in the lateral nasal wall at its posterior aspect near to middle turbinate. Biopsy is not recommended due to risk of bleeding [7]. Histopathologically, the tumor is composed of vascular and fibrous components. The vascular component is made up of thin vascular channels where the vessel wall is devoid of muscle layer. Thus, this tumor bleeds profusely due to the lack of contractile capacity of blood vessels.

JNA expresses Laminin- $\alpha$ which is considered as a marker for early angiogenesis. 


\section{Original Research Article}

Surgery is considered as the mainstay in the management of JNA. Various open surgical approaches have been employed traditionally for the resection of JNA like Transpalatine approach, Sardana's approach, Lateral rhinotomy, Midfacial degloving, and Neurosurgical approaches $[1,2,3,8]$. Now different endoscopic approaches like Modified Denkers, Medial maxillectomy, Transpterigoid are currently used for JNA removal. Endoscopic transnasal resection of a JNA was described by Kamel in 1996 to focus on improving minimally invasive endoscopic methods for removing JNA tumors. Endoscopic surgery has emerged as the preferred approach for small, intermediate size JNA [9]. For large advanced lesions, combined endonasal external approach is preferred.

Use of coblation in endoscopic nasal surgery has significantly improved and simplified the management of JNA. Coblation in JNA decreases chance of intraoperative bleeding, causes controlled debulking of the tumors, decreases requirements for multiple instrumentation, and improves visualization of surgical field as it has inbuilt suction apparatus [8,10]. Coblation is the plasma technology which creates relatively low temperature (60$70^{\circ} \mathrm{C}$ ) in surgical field which can coagulate and ablate the lesion simultaneously [10].
Control of bleeding intraoperatively is the most difficult part during JNA surgery. Tumor usually takes blood supply from sphenopalatine and internal maxillary artery. In large tumor, it may get feeding vessels from internal carotid artery. Hence, preoperative DSA (Digital subtraction angiography) is mandatory to know the nature of feeding vessels. Preoperative embolization of feeding vessels is required to get a good control of intraoperative bleeding. Different materials used for embolization are Polyvinyl Alcohol (PVA), gelfoam, coils, microspheres, onyx etc.

Preferred material for embolization in JNA is PVA. PVA particles are available in different sizes ranging from 300500 micron. PVA incites an intraluminal thrombosis with an associated inflammatory reaction.

There are many alternative modalities of treatment that include irradiation, hormones, receptor blockers and cytotoxic therapy. Radiotherapy has been a potent alternative to surgery in the management of JNA [11]. Radiotherapy of low dose (30 to 36 Gy) has been used for recurrent lesion not amenable to complete resection with acceptable morbidity. New technology like gamma knife radiosurgery and cyberknife are effective for lesion of limited size [7].

\section{Material and Method}

Setting: This is a study done in department of otorhinolaryngology, Kalinga Institute of Medical Sciences, Bhubaneswar.

Duration: Total duration of study is 5 years and 6 months, between January 2014 to June 2019.

Type of study: It is a retrospective study.

Sample size: It includes 12 patients of JNA.

\section{Inclusion criteria:}

All males between 5 to 20 years of age with nasal mass (confirmed by nasal endoscopy) and nasal bleeding

\section{Exclusion criteria:}

Infective causes, pattern of extension of mass, bone erosion (accessed by CT and MRI) and source of feeding vessels of mass (accessed by DSA) supporting the diagnosis of JNA.

Out of 12 patients, 2 were Radkowski stage I, 9 were Radkowski stage II and 1 was Radkowski stage III. Three patients (2 patients from stage IIB \& 1 patient from stage IIIA) were embolized out of 12 patients. After taking informed consent from the patients, detailed preoperative evaluation was done including history taking, clinical examination, endoscopic examination $\&$ cranial nerve examination. All patients were male between age group 5 to 20 years. All presented with progressive painless nasal obstruction and unprovoked epistaxis. Two patients have nasal mass protruding to the nasal cavity. None of the patients had check swelling. Blockage of ear and intermittent ear pain was seen in seven patients. On nasal endoscopy a smooth, reddish, lobulated mass in the nasal cavity was seen in all the cases.

Otoendoscopic picture of tympanic membrane of seven out of twelve patients showed presence of secretory otitis media (due to eustachian tube block). On oral examination, buldging of soft palate and trismus were not seen in any case. On examination of cranial nerve, none of the patients presented with cranial nerve palsies. CECT \& MRI was done to know bony erosion, tumor extension, skull base \& dural involvement (Figure 1: CT SCAN finding of an adolescent male with JNA showing moderately enhancing soft tissue mass in nasopharynx, sphenoid sinus, right pterygoid wedge and pterygopalatine fossa). DSA (Digital Subtraction Angiography) was done in all patients to identify the feeding vessels and to rule out feeders from internal carotid artery, any aberrant blood vessels supplying tumor. 
Original Research Article

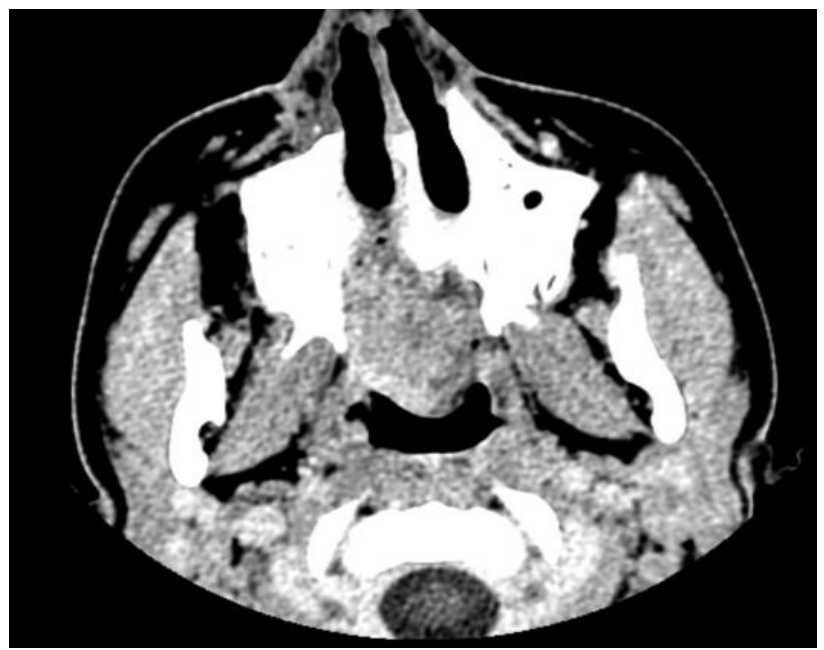

Fig.-1 (A): Tumor involving right pterygoid wedge and Pterygopalatine fossa.

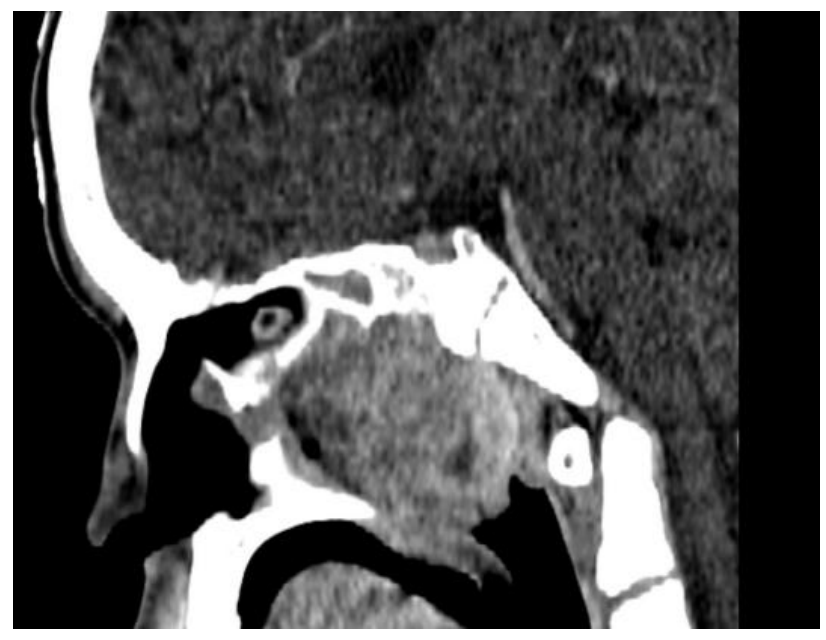

Fig.1 (B): Tumor involving sphenoid sinus and nasopharynx.

In three patients only, preoperative embolization was done. In all cases embolization was done by transarterial technique using gelfoam in 2 cases and PVA particle in 1 case (Figure 2: Pre and post embolization images of right internal maxillary artery). Absence of tumor blush can be seen in post embolization image). All JNA removal were done endoscopically using coblation.

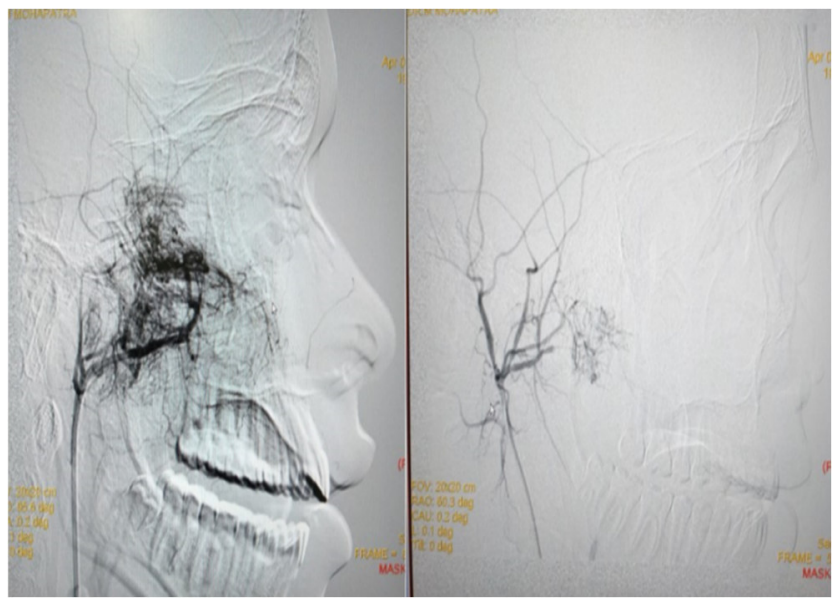

Fig.-2: Pre and Post embolization image of right internal maxillary artery. absence of tumor blush can be seen in postembolization image. 


\section{Original Research Article}

Surgical techniques: All cases were operated under general anaesthesia (hypotensive). In all cases patients were placed in reverse trendelenberg position and neck was secured in neutral position and head was slightly turned to right. In every patient nasal pack soaked in solution containing 1 in 10000 Adrenaline was placed in each nostril for 10 minutes. Use of topical vasoconstriction causes decongesion of the nasal mucosa and widens nasal space and minimizes bleeding. It provides enough space for manipulation of endoscope inside. 0 and 45 degree, $4 \mathrm{~mm}$ diameter \& $18 \mathrm{~cm}$ length Hopkins rod endoscope (Karl Storz) was used. Evac 70 Xtra HP coblation wand (Coblator II, Arthrocare corporation) was used. Medial maxillectomy and posterior septectomy was done first for a good exposure of tumor mass. Resection of posterior nasal septum widens the access in endoscopic tumor removal and defines tumor margins. (Figure 3: Excision of mass with coblator intraoperatively in a JNA patient). Debulking of tumor was done by using coblator Evac 70 Xtra HP wand. Ethmoidectomy and sphenoidotomy was done to access the posterior extent of tumor.

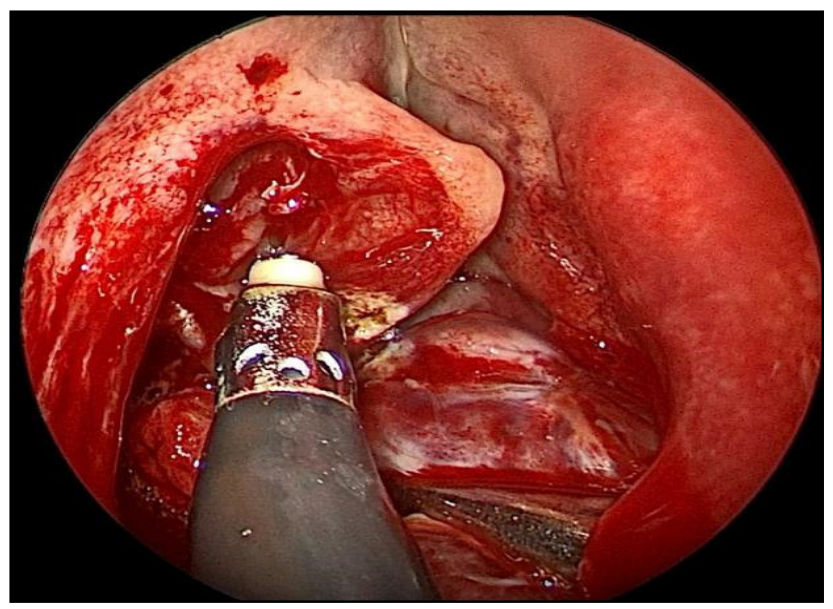

Fig.-3: Intraoperative Tumor mass dissected by Evac 70 Xtra HP wand.

Feeding vessels (Sphenopalatine and Internal maxillary artery) were cauterized by bipolar cautery. Early control of the main feeding vessels was of great value to assist further tumor resection. Blakesley forcep was used and gentle traction was applied to remove the part of the tumor in sphenoid sinus. In most of the cases, tumor was separated from the sphenopalatine foramen and inferior part of the sphenoid using the coblator device.

Pterygoid wedge and vidian canal were drilled out using diamond burr for complete removal of residual stump of tumor. The main tumor was delivered transorally due to its large size in four out of twelve cases.

Haemostasis was maintained and bilateral nasal packing with merocel pack of appropriate size was given in each nostril. Throughout the procedure, the tip of the coblator laterally was avoided while coblating near lamina papyracea or sphenoid sinus. The present study dissected along the pseudocapsule and avoided entering the tumor surface (capsule) to prevent severe bleeding due to high density of irregularly shaped vessels at the tumor surface. While dissecting bleeding was less at the centre of the tumor as it contains more amount of fibrous tissue and reduced density of blood vessels. For larger tumor septal window was created so that bi-nostril four-handed surgery technique was performed and whole nasopharyngeal part of the tumor was visualised properly.

Postoperative care: In all patients Antibiotic (Injection Amoxiclav) was given for 1 week, a nonopioid analgesic was given for 5 days, nasal pack removal was done after 48 hours. All patients were discharged within 1 week of operation. Post op nasal douching with normal saline twice a day for 30 days to prevent crusting was adviced. In each case, follow up was done after 1 month, 3 months and subsequent follow up after every 6 months. In each follow up diagnostic nasal endoscopy was done.

Follow up MRI was done 6 month post-operatively to know any recurrence. In addition to this, every patient was asked to maintain a good oral hygiene.

\section{Results}

All patients were male between age group 5 to 20 yrs. All patients were staged according to Radkowski staging system (Table 1). 
Original Research Article

Table-1: Radkowski staging system for Juvenile nasopharyngeal angiofibroma [12]

\begin{tabular}{|l|l|}
\hline Type & \multicolumn{1}{|c|}{ Description } \\
\hline IA & Limited to nose and nasopharynx \\
\hline IB & As in stage IA with extension into $>/=1$ sinus \\
\hline IIA & Minimal extension through sphenopalatine fossa and into medial pterigomaxillary fossa \\
\hline IIB & $\begin{array}{l}\text { Full occupation of pterigomaxillary fossa, displacing posterior wall of maxilla forward, orbit } \\
\text { erosion, displacement of maxillary artery branches }\end{array}$ \\
\hline IIC & Infratemporal fossa, cheek, posterior to pterigoid plate. \\
\hline IIIA & Minimal intracranial extension \\
\hline IIIB & Maximal intracranial extension cavernous sinus \\
\hline
\end{tabular}

A total 12 cases of JNA were operated by coblation assisted endoscopic approach. Out of 12 patients, 9 patients (Radkowski stage IB, IIA \& IIB) were operated without embolization and had a mean blood loss of $355 \mathrm{ml}$. Rest of the 3 patients (Radkowski stage IIB \& IIIA) were operated with embolization and had a mean blood loss of $470 \mathrm{ml}$. Overall mean blood loss was $385 \mathrm{ml}$. Blood transfusion was not required in any of our cases. Mean operative time was 200 min. All patients have achieved symptomatic relief and recovered without any complication. The mean duration of hospital stay was 5 days. Recurrence was seen in two patients (Table 2).

Table-2: Treatments and outcomes of all cases.

\begin{tabular}{|c|l|l|l|c|c|c|c|}
\hline $\begin{array}{c}\text { Age } \\
\text { Year) }\end{array}$ & Gender & Staging & $\begin{array}{c}\text { Preoperative } \\
\text { embolization }\end{array}$ & $\begin{array}{c}\text { Estimated } \\
\text { intraoperative } \\
\text { blood loss }\end{array}$ & $\begin{array}{c}\text { Operation } \\
\text { time } \\
\text { (Minutes) }\end{array}$ & $\begin{array}{c}\text { Duration of } \\
\text { hospital } \\
\text { stay }\end{array}$ & Recurrence \\
\hline 8 & Male & IB & Not done & $250 \mathrm{ml}$ & $150 \mathrm{Min}$ & 3 days & No \\
\hline 12 & Male & IB & Not done & $200 \mathrm{ml}$ & $180 \mathrm{Min}$ & 3 days & No \\
\hline 10 & Male & IIA & Not done & $350 \mathrm{ml}$ & $195 \mathrm{Min}$ & 5 days & No \\
\hline 15 & Male & IIA & Not done & $300 \mathrm{ml}$ & $180 \mathrm{Min}$ & 5 days & No \\
\hline 18 & Male & IIA & Not done & $400 \mathrm{ml}$ & $165 \mathrm{Min}$ & 5 days & No \\
\hline 14 & Male & IIA & Not done & $400 \mathrm{ml}$ & $195 \mathrm{Min}$ & 5 days & No \\
\hline 20 & Male & IIA & Not done & $350 \mathrm{ml}$ & $165 \mathrm{Min}$ & 5 days & No \\
\hline 17 & Male & IIB & Not done & $500 \mathrm{ml}$ & $230 \mathrm{Min}$ & 6 days & Yes \\
\hline 9 & Male & IIB & Not done & $450 \mathrm{ml}$ & $210 \mathrm{Min}$ & 6 days & No \\
\hline 18 & Male & IIB & Done & $400 \mathrm{ml}$ & $210 \mathrm{Min}$ & 5 days & 5 days \\
\hline 20 & Male & IIB & Done & $400 \mathrm{ml}$ & $210 \mathrm{Min}$ & No \\
\hline 14 & Male & IIIA & Done & $600 \mathrm{ml}$ & $265 \mathrm{Min}$ & 7 days & Yes \\
\hline
\end{tabular}

\section{Discussion}

Preoperative evaluation of JNA before resection is of paramount importance. Evaluation is done by history, nasal endoscopic examination of mass followed by radiology (CT/MRI). Progressive unilateral nasal obstruction, unprovoked intermittent nasal bleeding in an adolescent male is the typical history of JNA. The Endoscopic finding of a small, hypervascular lesion in an adolescent boy that originates behind the middle turbinates strongly suggests a diagnosis of JNA and usually confirmed by CECT and MRI. MRI is more accurate in accessing Intracranial extension. Tumor extension by CT and MRI and tumor vascularity by DSA will help the surgeon to plan for surgery preoperatively. Biopsy is not recommended in these vascular tumors. Pattern of tumor extension by CT and MRI will help in diagnosis. In radiological investigation, features of JNA are:

1) The area of origin invariably located at the level of the pterygopalatine fossa.

2)It's hypervascular appearance after contrast enhancement.

3) It's pattern of growth 


\section{Original Research Article}

4) On MRI, the presence on both T1- and T2-weighted sequences of several signal voids within the lesion, indicating major intralesional vessels, further corroborates a diagnosis of juvenile angiofibroma [7].

It can spreads to all adjacent areas. Medially to Nasal cavity, Nasopharynx and Sphenoid sinus. Laterally to Pterygomaxillary fissure, Infratemporal fossa \& cheek (tumour growth beyond the maxillary sinus will present as facial swelling). Superiorly through Infraorbital fissure it can enter orbit (causing proptosis and/or optic nerve compression with visual disturbance) and Intra-cranial tumour spread (advanced stages). In cases of intra-cranial tumour growth, JNA are mainly located in the extradural space.

It is histologically characterised by vascular endotheliumlined spaces embedded in a fibrous stroma. The vascular component is formed by a thin walled vascular channel that completely lacks muscular coat and larger vessels that have sparse incomplete muscle layer. Elastic fibers are characterstically absent. Smaller vessels are lined by a thin layer of endothelial cells, have patent lumina and are easily prone to rupture and bleed profusely. Thus, epistaxis in JNA seems to be a result of the fragility of these vessels. Although the tumor is histopathologically classified as a benign lesion, bony erosion of the pterigoid wedge, the clivus and the sphenoid sinus floor are common hallmark of JNA [1].

Surgery is the main treatment modality of JNA. Now a days, endoscopic approach is the preferred approach. Open surgical approach is usually required in larger tumors those are difficult to remove by endoscopic approach. Transnasal endoscopic approach has been successfully used over the past few decades in the treatment of neoplasm of nasopharynx [13]. It permits a direct approach to the neoplasm and provide multi angled panoramic view, good illumination, access to deep hidden areas, also reduces the risk of complications and risk of leaving behind residual tumor after surgery [13].

Endoscopic resection of JNA can be assisted by laser, coblation or ultrasonic scalpel. Use of coblation in endoscopic removal of JNA is increasing day by day because of minimal invasive surgery. The coblator is a bipolar, radiofrequency electrosurgical system [14]. Coblation uses plasma technology where a single instrument (Wand) is used for coagulation, ablation, saline irrigation and suctioning [15]. Coblation has many advantages like decrease intraoperative blood loss, short operative time, minimising instrumentation, proper visualization of intraoperative field, less hospital stay, low postoperative morbidity and avoidance of osteotomies which provide better cosmesis.
Intraoperative bleeding is considered one of the most challenging aspect in the management of JNA. In the early stages, the tumor takes supply from sphenopalatine artery and internal maxillary artery [1]. In advanced stages, further branches of external carotid arteries (i.e. ascending pharyngeal artery) contribute to tumor blood supply. Internal carotid artery, vertebral artery have to be considered as additional feeders, especially in large JNA [1].

Hence, careful angiographic evaluation of bilateral ICA \& ECA is strongly recommended [1]. So preoperative angiography with superselective embolization (with Polyvinyl alcohol particle) of feeding vessels provide good control of intraoperative bleeding, decreases intraoperative time and preserve anatomical integrity $[1,7]$. Preoperative embolization is done within 24 to 48 hours of surgery.

Choice of embolic material in JNA is Polyvinyl alcohol. PVA have advantages, particularly for embolization of tumors, because the agent flows to the bleeding site and occlude numerous vessels from a single injection. Gelfoam have advantage that it is cheaper than other agents.

Other than arterial bleeding, venous bleeding is also encountered intraoperatively. These occur from the mucosa, pterygoid plexus, cancellous bone and cavernous sinus. This type of bleeding can be prevented by diamond burr drilling, a good communication between the anesthesiologist and surgeon to anticipate blood loss and use of four handed technique.

Salina et al reported in their study, three patients with Stage I, II, IIIA has average blood loss of 0.9 liter with coblation, mean operating time of $2.3 \mathrm{hrs}$, average length of hospital stay of 2 days [2].

In the study done by Ruiz JW et al, Coblation assisted endoscopic tumor resection of Radkowski IIB tumor (nonembolised) required $2 \mathrm{hr}$ and $40 \mathrm{~min}$ of total surgical time and blood loss of $130 \mathrm{ml}$. In Daniel E et al study, three cases were done by using coblation (embolized). Cases were Radkowski IIA, IIB \& IIIA.

The blood loss for these three cases were $75 \mathrm{ml}, 350 \mathrm{ml}, 300$ $\mathrm{ml}$ and the operative time were $161 \mathrm{~min}, 190 \mathrm{~min}$ and $6 \mathrm{hrs}$ respectively. Ye L, Zhou X, Li J, Jin J reported the mean tumour resection time for coblation and traditional endoscopic instruments as 87 and 136 minutes, respectively $(t=9.962, p<0.001)$ and mean intra-operative blood loss was 121 and $420 \mathrm{ml}$, respectively $(\mathrm{t}=28.944, \mathrm{p}<0.001)$, a significant difference.

This is suggestive of significantt difference in blood loss intraoperatively when compared with traditional methods 


\section{Original Research Article}

[16]. Janakiram $\mathrm{TN}$ et al reported that 15 patients were operated by binostril four handed endoscopic technique without embolization. Average surgery time duration was 1 h 41 min. Mean blood loss was $67.2 \mathrm{ml}$. Mean hospitalization time was 3.66 days [17].

These studies are comparable to the present study where mean blood loss is $355 \mathrm{ml}$ (Radkowski stage IB, IIA \& IIB) and $470 \mathrm{ml}$ (Radkowski stage IIB \& IIIA) in nonembolized and embolized case respectively. Overall mean blood loss is $385 \mathrm{ml}$.

Increased blood loss in embolized patient is due to the advanced stage (IIB, IIIA) of tumor. Mean operative time is $200 \mathrm{~min}$. The mean duration of hospital stay was 5 days. Recurrence was seen in two cases.

Limitations of the present study- As surgery require a disposable wand which has an extra financial burden on patients so in few cases, coblator couldn't be used in those who could not afford it, and these cases weren't included in the present study.

As the present study experienced recurrence of two cases in large tumors. So, it requires a greater number of studies to prove efficacy of endoscopic management in larger tumor.

Roger $\mathrm{G}$ et al reported in their study, out of 20 patients (operated exclusive by endoscopic approach), seven patients (large tumors) had recurrence which were managed later by open method [18].

\section{Conclusion}

JNA is a highly vascular, aggressive tumor in which preoperative radiological imaging is mandatory for tumor staging and preoperative planning. Coblation is safe and effective tool in endoscopic removal of JNA which helps in debulking of tumor, reducing intraoperative blood loss and minimising frequent and multiple instrumentation.

Coblator can dissect through and debulk the tumor, despite its extreme vascularity. Thus coblation reduces the overall operative time.

Preoperative embolization further helps in reducing intraoperative bleeding. It can be performed with minimal morbidity.

\section{What the study adds to the existing knowledge?}

This study will encourage use of coblator in dissection of vascular tumors of nose and paranasal sinuses like angiofibroma without much of complications and mortality.

\section{Author's contributions}

Dr. Khageswar Rout: Concept, design, planning, analysis, review and editing of manuscript. He was the primary surgeon in each case.

Dr. Pradipt Ranjan Sahoo: Study concept, design, data collection, data curation, preparation of manuscript and critical review and editing of manuscript. He was the 1st assisting surgeon in all cases.

Dr. Kumari Jyoti Mani: Design, data collection, preparation of manuscript, original draft preparation, review and editing of manuscript. She was the 2 nd assisting surgeon.

Funding: No funding sources

Conflict of interest: None declared

Ethical Approval: This study was approved by the Institutional Ethics Committee

\section{References}

1. Schick B. Juvenile Angiofibroma. In: Watkinson JC,Clarke RW(Eds). Scott-Brown's Otorhinolaryngology Head \& Neck Surgery. $8^{\text {th }}$ ed. 2019. p1265-67.

2. Husain S, Mesran I, Zaifullah S, Gendeh BS, Yunos MR. Endoscopic removal of juvenile nasopharyngeal angiofibroma: conventional versus coblation-assisted. Rawal Med J. 2016;41(1):90-94.

3. Ruiz JW, Saint-Victor S, Tessema B, Eloy JA, Anstead A. Coblation assisted endoscopic juvenile nasopharyngeal angiofibroma resection. Int $\mathrm{J}$ Pediatr Otorhinolaryngol. 2012; 76(3): 439-442. doi: https://doi.org/10.1016/j.ijporl. 2011.11 .005 .

4. Ikubor JE, Okolugbo NE, Okhakhu AL. Radiological features of juvenile nasopharyngeal angiofibroma. J West Afr Coll Surg. 2013;3(4):84-91.

5. Jankiram N, Sharma SB, Samavedam UC. History of Juvenile Nasopharyngeal Angiofibroma: A Surgeon's Odyssey. In: Jankiram N(Eds). Juvenile Nasopharyngeal Angiofibroma. Thieme Medical and Scientific Publisher Private Limited 2017, p 3-9.

6. Masilamani S. Pathology of juvenile Nasopharyngeal Angiofibroma. In: Jankiram N(Eds). Juvenile Nasopharyngeal Angiofibroma. Thieme Medical and Scientific Publisher Private Limited 2017, p 105-110.

7. Nicolai P,Castelnuovo P.Benign Tumor of Sinonasal Tract. Cummings Otolaryngology Head and Neck Surgery, $6^{\text {th }}$ ed. Elsevier 2015, p 744-746. 


\section{Original Research Article}

8. Tiwari PK, Teron P, Saikia N, Saikia HP, Bhuyan UT, Das D. Juvenile nasopharyngeal angiofibroma: A rise in incidence. Indian J Otolaryngol Head Neck Surg. 2016; 68 (2): 141-148. doi https:// doi.org/10. 1007/s12070-0150898-4.

9. Vinod G, Shashikant M, Mohammed S, Samir B. Coblator Assisted Endonasal Endoscopic Excision of Juvenile Nasopharyngeal Angiofibroma. Int J Contemp Med Res. 2016;3(9):2622-2624.

10. Pierson B, Powitzky R, Digoy GP. Endoscopic Coblation for the treatment of advanced juvenile nasopharyngeal angiofibroma. Ear, Nose \& Throat J. 2012; 91(10):432-438. doi: https://doi.org/10.1177/ 01455613120 9101007.

11. Rilke RM. Juvenile Nasopharyngeal Angiofibroma: Adjuvant Treatment Modalities and Future consideration. In:Jankiram N(Eds). Juvenile Nasopharyngeal Angiofibroma. Thieme Medical and Scientific Publisher Private Limited 2017, p 276-284.

12. Jankiram N, Sharma SB, Samavedam UC. Staging System of Juvenile Nasopharyngeal Angiofibroma. In: Jankiram N(Eds). Juvenile Nasopharyngeal Angiofibroma. Thieme Medical and Scientific Publisher Private Limited 2017 p 87-102.

13. Pryor SG, Moore EJ, Kasperbauer JL. Endoscopic versus traditional approaches for excision of juvenile nasopharyngeal angiofibroma. The Laryngosc. 2005; 115
(7):1201-1207. doi: https://doi.org/ 10.1097/01.MLG. 0000162655.96247 .66 .

14. Mancini PF. Coblation: a new technology and technique for skin resurfacing and other aesthetic surgical procedures. Aesthetic Plast Surg. 2001;25(5):372-377. doi: https:// doi.org/ 10.1007/s002660010148.

15. Cannon DE, Poetker DM, Loehrl TA, Chun RH. Use of coblation in resection of juvenile nasopharyngeal angiofibroma. Annals of Otology, Rhinol Laryngol. 2013; 122(6):353-357. doi: https://doi.org/10.1177/ 00034894 1312200601 .

16. Ye L, Zhou X, Li J, Jin J. Coblation-assisted endonasal endoscopic resection of juvenile nasopharyngeal angiofibroma. J Laryngol Otol. 2011;125(9):940-944. doi: https:// doi. org/10.1017/S0022215111001344.

17. Janakiram TN, Sharma SB, Panicker VB. Endoscopic excision of non-embolized juvenile nasopharyngeal angiofibroma: Our technique. Indian J Otolaryngol Head Neck Surg. 2016;68(3):263-269. https://doi.org/ 10.1007/ s12070-016-1013-1.

18. Roger G, Huy PT, Froehlich P, Van Den Abbeele T, Klossek JM, Serrano E, Garabedian EN, Herman P. Exclusively endoscopic removal of juvenile nasopharyngeal angiofibroma: trends and limits. Arch Otolaryngol Head Neck Surg. 2002;128(8):928-935. doi: https :// doi.org/10.1001/archotol.128.8.928.

\section{How to cite this article?}

Rout K, Mani K.J, Sahoo P.R. Coblation Assisted Endoscopic Excision of Juvenile Nasopharyngeal Angiofibroma- An Institutional Observational Study. Trop J Ophthalmol Otolaryngol.2019;4(8):488-495.doi:10.17511/jooo.2019.i08.06 